\title{
Adequate antibody response to BioNTech COVID vaccine in a multiple sclerosis patient treated with siponimod
}

\author{
Gulnaz Siddiqui ${ }^{*}$ (D), Heidi Maloni ${ }^{2}$ and Victor E. Nava ${ }^{3}$
}

Keywords: COVID-19, Multiple sclerosis, Anti-COVID-19 vaccination, Sphingosine 1-phosphate receptor, Modulators, Disease-modifying therapy

To the editor,

We appreciated Mansoor and colleagues review entitled "COVID-19 pandemic and the risk of infection in multiple sclerosis patients on disease-modifying therapies: "what the bleep do we know?"' [1]. The authors examined available evidence guiding the management of multiple sclerosis (MS) patients during this pandemic, indicating that sphingosine 1-phosphate receptor modulators (S1PRM), including siponimod, could increase the risk of COVID-19 infection due to immunosuppression.

However, emerging data suggest that MS patients mount a humoral and cellular immune response even while receiving disease-modifying therapies (DMT) [2, 3]. For instance, retrospective data [2] from MS patients receiving S1PRM who completed two doses of antiSARS-CoV-2 vaccination (either Pfizer or Moderna) showed positive anti-spike $(S)$ protein antibody titers (Abbott or Roche SARS-CoV-2 IgG assay) determined forty-five and half days (average) after immunization. A wide range (16.1-80.4) of IgG index was observed. The incidence of COVID-19 infection, however, was not analyzed [2]. Surprisingly, the study suggested that based on "real-life experience", S1PRM could potentially hamper an effective humoral response to anti-COVID-19 vaccination in MS patients, which may unnecessarily discourage urgent immunization efforts.

\footnotetext{
*Correspondence: Gulnaz.sidd@gmail.com

${ }^{1}$ Department of Biomedical Sciences and Department of Pathology,

University of Missouri, Kansas City, MO, USA

Full list of author information is available at the end of the article
}

At the Veterans Affairs Medical Center, Washington $D C$, we have followed a 73-year-old man with active progressive MS (Expanded Disability Status Scale of 5.0) since 1995 . He was initially treated in 1998 with glatiramer acetate, which was switched to siponimod ( $2 \mathrm{mg}$ daily orally) since December 2019, achieving stabilization of neurocognitive decline. His absolute lymphocyte count was decreased $(0.3 \mathrm{~K} / \mathrm{cmm}$, reference range $0.8-$ $3.1 \mathrm{~K} / \mathrm{cmm}$ ) since July 2020 . He received two doses of the BNT162b2 Pfizer vaccine (2/1/2021 and 2/22/2021), and his quarterly laboratory work-up (complete cell blood counts, serum immunoglobulins, thyroid function, liver function, Chem 7, urine analysis, and fecal occult blood) has been unremarkable, except for stable mild lymphopenia $(0.3 \mathrm{~K} / \mathrm{cmm}, 7 / 26 / 21)$ and mildly decreased IgM of $36 \mathrm{mg} / \mathrm{dl}$ (reference range 43-279 mg/dl). Additional immune evaluation (including lymphocyte subsets) was not performed. Anti-COVID-19 antibody testing was performed about 160 days after completion of vaccination $(6 / 28 / 2021)$ and was positive for $\mathrm{S}(42.3 \mathrm{U} / \mathrm{ml}$ units, Eclisys, Roche) and negative for anti-nucleocapsid (0 U/ $\mathrm{ml}$, Eclisys, Roche) proteins, indicating adequate immune response to vaccination and absence of prior SARSCoV-2 infection.

Universal consensus on anti-COVID-19 vaccination in MS patients treated with DMT is still emerging [2]. PubMed does not yield real-life data on the use of siponimod in MS patients exposed to COVID-19 or vaccination against it. Diminished immune response to non-COVID-19 vaccines have been reported after treatment with siponimod [4], which may be less 
immunosuppressive than fingolimod (another S1RP inhibitor). Caution is necessary while using DMT in MS [1-3]. One must also consider that many studies are limited to static analysis of humoral responses without correlates with cell blood counts or neutralizing activity [2]. Further research is necessary to determine if DMT hamper appropriate immune responses, especially since the BNT162b2 vaccine also elicits T-cell immunity [5]. In summary, our experience suggests that siponimod may not significantly alter humoral immunity against COVID-19 vaccination, and may contribute to encourage vaccination against this pandemic in MS patients receiving DMT.

\section{Abbreviations}

COVID-19: Coronavirus disease 2019; MS: Multiple sclerosis; S1PRM: Sphingosine 1-phosphate receptor modulators; DMT: Disease-modifying therapies; SARS-CoV-2: Severe acute respiratory syndrome coronavirus 2; Chem-7: Basic metabolic panel; BNT162b2: Pfizer-BioNTech COVID-19 vaccine.

\section{Acknowledgements}

Not applicable.

\section{Authors' contributions}

GS: design, literature search, discussion, first draft, critical comments. VN: design, literature search, discussion, critical comments, final approval. All authors read and approved the final manuscript.

\section{Funding}

Not applicable.

\section{Availability of data and materials}

The data sets supporting the conclusion of this article are included within the article.

\section{Declarations}

Ethics approval and consent to participate

Not applicable.

\section{Consent for publication}

Not applicable.

\section{Competing interests}

The authors confirm that they have no competing interests.

\section{Author details}

'Department of Biomedical Sciences and Department of Pathology, University of Missouri, Kansas City, MO, USA. ${ }^{2}$ Department of Neurology, Department of Veterans Affairs Medical Center, Washington, DC, USA. ${ }^{3}$ Department of Pathology, Department of Veterans Affairs Medical Center, Washington, DC, USA.

Received: 7 November 2021 Accepted: 30 November 2021

Published online: 14 December 2021

\section{References}

1. Mansoor S, Kelly S, Murphy K, Waters A, Siddiqui NS. COVID-19 pandemic and the risk of infection in multiple sclerosis patients on disease modifying therapies: "what the bleep do we know? Egypt J Neurol Psychiatry Neurosurg. 2020;56(1):44.

2. Bigaut K, Kremer L, Fleury M, Lanotte L, Collongues N, de Seze J, et al. Impact of disease-modifying treatments on humoral response after COVID-19 vaccination: a mirror of the response after SARS-CoV-2 infection. Rev Neurol (Paris). 2021:177:1237-40.

3. Al Jumah M, Abulaban A, Aggad H, Al Bunyan R, AlKhawajah M, Al MalikY, Almejally M, Alnajashi H, Alshamrani F, Bohlega S, Cupler EJ, ElBoghdady A, Makkawi S, Qureshi S, Shami S, et al. Managing multiple sclerosis in the Covid 19 era: a review of the literature and consensus report from a panel of experts in Saudi Arabia. Mult Scler Relat Disord. 2021;51:102925.

4. Ufer M, Shakeri-Nejad K, Gardin A, Su Z, Paule I, Marbury TC, Legangneux $\mathrm{E}$, et al. Impact of siponimod on vaccination response in a randomized, placebo-controlled study. Neurol Neuroimmunol Neuroinflamm. 2017:4(6):e398.

5. Sahin U, Muik A, Derhovanessian E, Vogler I, Kranz LM, Vormehr M, Baum A, Pascal K, Quandt J, Maurus D, Brachtendorf S, Lörks V, Sikorski J, Hilker R, Becker D, Eller A, Grützner J, Boesler C, Rosenbaum C, Kühnle M, Luxemburger U, Kemmer-Brück A, Langer D, Bexon M, Bolte S, Karikó K, Palanche T, Fischer B, Schultz A, Shi P, Fontes-Garfias C, Perez JL, Swanson KA, Loschko J, Scully I, Cutler M, Kalina W, Kyratsous CA, Cooper D, Dormitzer P, Jansen KU, Türeci Ö, et al. COVID-19 vaccine BNT162b1 elicits human antibody and TH1 T cell responses. Nature. 2020;586:594-9.

\section{Publisher's Note}

Springer Nature remains neutral with regard to jurisdictional claims in published maps and institutional affiliations.

\section{Submit your manuscript to a SpringerOpen ${ }^{\circ}$ journal and benefit from:}

- Convenient online submission

$\checkmark$ Rigorous peer review

- Open access: articles freely available online

- High visibility within the field

- Retaining the copyright to your article

Submit your next manuscript at $\boldsymbol{\nabla}$ springeropen.com 